\title{
Variation in growth, photosynthesis and water-soluble polysaccharide of Cyclocarya paliurus under different light regimes
}

\author{
Wanxia Yang ${ }^{(1-2)}$, \\ Yang Liu ${ }^{(1)}$, \\ Shengzuo Fang ${ }^{(1-2)}$, \\ Haifeng Ding ${ }^{(1)}$, \\ Mingming Zhou ${ }^{(1)}$, \\ Xulan Shang ${ }^{(1-2)}$
}

\begin{abstract}
As a highly valued and multiple function tree species, Cyclocarya paliurus is planted and managed for timber production and medical use. Responses of growth, photosynthesis and phytochemical accumulation to light environment are useful informations to determine suitable habitat conditions for the cultivation of $C$. paliurus. A split-plot design with five light quality and three light intensity levels was adopted to compare the variations in plant growth, photosynthesis and water-soluble polysaccharide yield in $C$. paliurus leaves. Both light intensity and quality treatments significantly affected total biomass, photosynthetic rate and water-soluble polysaccharide yield in $C$. paliurus leaves. Treatments under red light and blue light with $1000 \mu \mathrm{mol} \mathrm{m} \mathrm{m}^{-2} \mathrm{~s}^{-1}$ achieved the highest values of biomass growth, photosynthetic rate, specific dry leaf mass per area and accumulation of water-soluble polysaccharide. These results indicate that red light and blue light with higher light intensity level were effective for increasing plant growth, photosynthesis and production of water-soluble polysaccharide in $C$. paliurus leaves. Manipulating light conditions might be an effective means to improve biomass and achieve higher water-soluble polysaccharide yield in $C$. paliurus plantations.
\end{abstract}

Keywords: Cyclocarya paliurus, Environmental Factor, Biomass Production, Phytochemicals, Photosynthesis

\section{Introduction}

Cyclocarya paliurus (Batal) Iljinskaja belongs to the Juglandaceae family and is widely distributed in mountainous regions of sub-tropical China (Fang et al. 2006). Leaves of this plant are traditionally used in China as a medicine or nutraceutical tea because of its unique taste (Birari \& Bhutani 2007, Fang et al. 2011). Many studies have demonstrated that $C$. paliurus has a variety of bioactivities, including hypoglycemic activity (Kurihara et al. 2003), antihypertensive activity (Xie et al. 2006), anti-HIV-1 (Zhang et al. 2010), antioxidant activity (Xie et al. 2010), and anticancer (Xie et al. 2013). However, most studies on C. paliurus were focused on plant compounds (including triterpenoids, flavonoids, steroids and saponins) and the extract activities whereas less attention was paid to the silvics of the species (Deng et al. 2012, 2015).

Light intensity and quality are important environmental factors for plant growth and development (Yu et al. 2016). Specifically, changes in light quality strongly affect plant morphological, physiological, and biochemical parameters due to the spectral properties of tissue pigments (Fan et al. 2013). However, the responses of plants to light quality are species specific (Cope \& Bugbee 2013). For example, Ouyang et al. (2003) reported that Cistanche deserticola cultured under blue light achieved higher biomass than those under red light. Yan et al. (2004) demonstrated that red light improved salidroside production and root growth of Rhodiola sachalinensis. However, Johkan et al. (2012) reported that green light was effective in promoting photosynthesis and plant growth of Lactuca sativa. Thus, it is necessary to determine the optimum light condi-

(1) College of Forestry, Nanjing Forestry University, Nanjing 210037 (P. R. China); (2) CoInnovation Center for Sustainable Forestry in Southern China, Nanjing Forestry University, Nanjing 210037 (P. R. China)

@ Shengzuo Fang (fangsz@njfu.edu.cn)

Received: Aug 02, 2016 - Accepted: Jan 19, 2017

Citation: Yang W, Liu Y, Fang S, Ding H, Zhou M, Shang X (2017). Variation in growth, photosynthesis and water-soluble polysaccharide of Cyclocarya paliurus under different light regimes. iForest 10: 468-474. - doi: 10.3832/ifor2185-010 [online 2017-04-04]

Communicated by: Gianfranco Minotta tions for better growth of $C$. paliurus.

Polysaccharides are very common natural polymers in plants, animals and microorganisms (Xiao et al. 2011, Cui et al. 2013). Recently, polysaccharides from plants have attracted more and more attention due to their extensive biological activities, such as hypoglycemic activity (Wang et al. 2001), free-radical-scavenging activity (Cui et al. 2013), anticancer activity (Xie et al. 2013), and improvement of immunomodulation activity (Huang \& Ning 2010). Due to its biological activities, polysaccharide from $C$. paliurus leaves have become a focal point for research and development. The structure and antioxidant activities of polysaccharide as well as sulfated polysaccharides from C. paliurus leaves had been investigated by Xie et al. (2010, 2015). Fu et al. (2015) also reported the seasonal and genotypic variation of leaf polysaccharide accumulation in C. paliurus, whereas knowledge of the environmental effects on polysaccharide accumulation in C. paliurus is limited.

The aims of this study were to quantify and compare the influences of varying light quality with different light intensities on plant growth, photosynthetic capacity, and water-soluble polysaccharide accumulation in C. paliurus leaves. Findings from the study are needed to better understand the responses of $C$. paliurus growth to differential light environment, and to provide a theoretical basis for standardized cultivation of C. paliurus plants. 
Fig. 1 - Relative spectral irradiance of the LED

lamps used. (WL): white light; (BL): blue light; $(\mathrm{RL})$ : red light; $(\mathrm{GL})$ : green light; $(\mathrm{PL})$ : purple light.

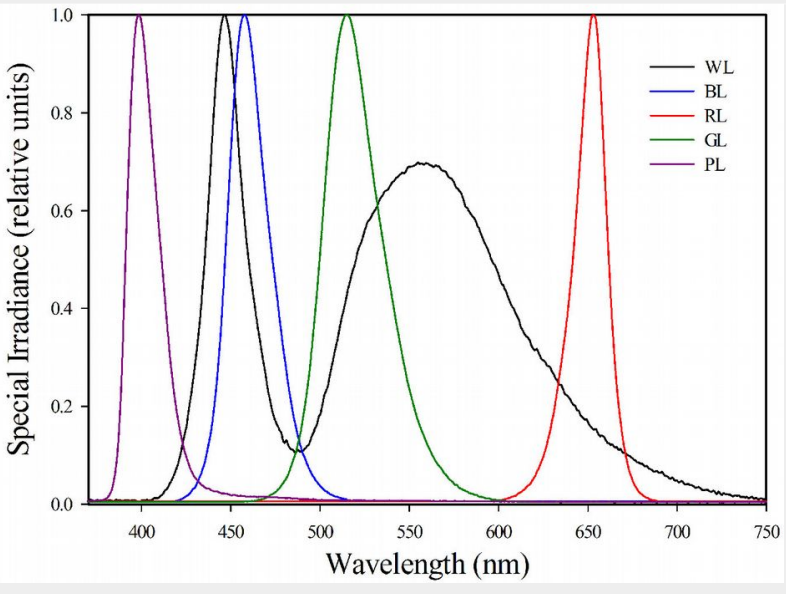

\section{Materials and methods}

Plant material and growth conditions

Seeds of $C$. paliurus were collected from Tonggu $\left(30^{\circ} 73^{\prime} \mathrm{N}, 116^{\circ} 47^{\prime} \mathrm{E}\right)$, Jiangxi province, China in late October 2014 and were subjected to chemical scarification, exogenous gibberellin $A_{3}\left(G_{3}\right)$ treatments, and stratification treatments in early January 2015, according to the method proposed by Fang et al. (2006). After a 3 month stratification treatment, the germinated seeds were transplanted into plastic pots $(8.5 \mathrm{~cm}$ inner-diameter, $10 \mathrm{~cm}$ height, with holes in the bottom, one seedling per pot) filled with a substrate mixture of perlite: fowl manure: peat: soil (2: 2: 4: $2, \mathrm{v} / \mathrm{v} / \mathrm{v} / \mathrm{v})$. The substrate was a loam with $\mathrm{pH} 6.44$, organic matter content of $73.3 \mathrm{~g} \mathrm{~kg}^{-1}$, total $\mathrm{N}$ content of $72.35 \mathrm{~g} \mathrm{~kg}^{-1}$, total P content of $2.19 \mathrm{~g}$ $\mathrm{kg}^{-1}$, and total $\mathrm{K}$ content of $9.55 \mathrm{~g} \mathrm{~kg}^{-1}$. Eight weeks later, plants were moved into climate chamber and then exposed to LED lamps (Guangdong Philips Lamp Co., China).

A split-plot randomized design was used to establish three light intensity levels and five light quality treatments. Three light intensity treatments were subjected to three intensity regimes: $L_{1}(500 \pm 30 \mu \mathrm{mol}$ $\left.\mathrm{m}^{-2} \mathrm{~s}^{-1}\right)$, L2 $\left(750 \pm 30 \mu \mathrm{mol} \mathrm{m} \mathrm{m}^{-2} \mathrm{~s}^{-1}\right)$, and L3 $\left(1000 \pm 30 \mu \mathrm{mol} \mathrm{m} \mathrm{m}^{-2} \mathrm{~s}^{-1}\right)$, respectively. The light intensity of LED lamps in each treatment was measured by $\mathrm{LI}-6400^{\circledR}$ system
(Li-Cor, Lincoln, NE, USA). Five light quality treatments were $\mathrm{WL}$ (white light), BL (blue light), RL (red light), GL (green light) and PL (purple light), respectively. Spectral features of the LED lamps were recorded by means of a NIR-VIS spectrometer (Ocean Optics, USA) and reported in Fig. 1. Each treatment contains 5 replications and 8 plants per replication (plastic pot). All treatments were kept at $25 \pm 2{ }^{\circ} \mathrm{C}$ and $60 \%$ relative humidity $(\mathrm{RH})$ during the day, $22 \pm$ $2{ }^{\circ} \mathrm{C}$ and $70 \% \mathrm{RH}$ at night with a $12 \mathrm{~h}$ dark/light photoperiod. The plants were kept well watered once every two days until the end of the experiment.

\section{Growth and biomass assessment}

After the growth of 5 months in the chamber, growth and biomass assessments of the plants were conducted on October 20, 2015. Intact C. paliurus seedlings in each treatment ( 5 seedlings) were harvested and separated into shoots and roots for biomass and water-soluble polysaccharide analysis. The leaf area (LA) $\left(\mathrm{cm}^{2}\right)$ of the third and fourth fully-expanded leaves from the top of the shoots was measured at the same time with an area meter (Li-Cor Model $\left.3100^{\circledR}\right)$. Biomass samples were dried $\left(70^{\circ} \mathrm{C}, 48 \mathrm{~h}\right)$ to constant weight and weighed. The total dry mass of each was calculated as the sum of leaf, stem, and root dry weights. The specific leaf mass (SLM) was calculated by

Tab. 1 - Summary of significance levels (Two-way ANOVA) for the effects of light quality, light intensity and their interaction on biomass production, water-soluble polysaccharide content and water-soluble polysaccharide yield in Cyclocarya paliurus leaves.

\begin{tabular}{llcccccc}
\hline & & \multicolumn{2}{c}{ Biomass $(\mathbf{g})$} & & \multicolumn{3}{c}{ Polisaccharide } \\
\cline { 3 - 7 } Source & & Root & Stem & Leaf & Total & $\begin{array}{c}\text { Content } \\
\left.\text { (mg g }^{-1}\right)\end{array}$ & $\begin{array}{c}\text { Yield } \\
\left.\text { (mg plant }^{-1}\right)\end{array}$ \\
\hline Light & $\mathrm{df}$ & 4 & 4 & 4 & 4 & 4 & 4 \\
quality & MS & 30.887 & 64.049 & 135.883 & 69.486 & 34.464 & 72.059 \\
(A) & Prob & $<0.001$ & $<0.001$ & $<0.001$ & $<0.001$ & 0.001 & $<0.001$ \\
Light & df & 2 & 2 & 2 & 2 & 2 & 2 \\
intensity & MS & 98.818 & 204.066 & 177.098 & 224.107 & 41.079 & 323.053 \\
(B) & Prob & 0.001 & $<0.001$ & $<0.001$ & 0.001 & $<0.001$ & $<0.001$ \\
Interaction & df & 8 & 8 & 8 & 8 & 8 & 8 \\
$($ A $\times$ B) & MS & 5.474 & 5.123 & 5.160 & 6.899 & 12.170 & 9.818 \\
& Prob & $<0.001$ & $<0.001$ & $<0.001$ & $<0.001$ & $<0.001$ & $<0.001$ \\
\hline
\end{tabular}

dividing dry leaf weight by corresponding leaf area (LA - Tang et al. 2015).

\section{Measurement of photosynthetic} parameters

Fully developed leaves from the top of the shoots were randomly selected for gas exchange measurements, using a $\mathrm{LI}-6400^{\circledR}$ portable photosynthesis system (LiCor Inc., USA) with a standard leaf chamber equipped with a 6400-02B LED light source (LI6400). Measurements were conducted at an air concentration of $21 \% \mathrm{O}_{2}, 380 \mu \mathrm{mol}$ $\mathrm{mol}^{-1} \mathrm{CO}_{2}, 1000 \mu \mathrm{mol} \mathrm{m} \mathrm{m}^{-2} \mathrm{~s}^{-1}$ photosynthetically active radiation (PAR), 50\% relative humidity and a temperature of $25 \pm 2{ }^{\circ} \mathrm{C}$. Photosynthetic rate $(\mathrm{Pn})$ and stomatal conductance (gs) were recorded.

\section{Extraction and measurement of water- \\ soluble polysaccharide}

Extraction of polysaccharide in C. paliurus leaves was carried out as described previously by Fu et al. (2015) with slight modifications. Each sample $(0.5 \mathrm{~g})$ of leaves was extracted with $30 \mathrm{ml}$ of $70 \%$ ethanol at 70 ${ }^{\circ} \mathrm{C}$ for $60 \mathrm{~min}$ to remove most pigments, small molecular sugars and impurities. The insoluble residues were separated, dried and then extracted twice with $20 \mathrm{ml}$ distilled water at $100{ }^{\circ} \mathrm{C}$ for $75 \mathrm{~min}$. The extracts were filtered and the filtrate was centrifuged at $5000 \times g$ for 15 min. Finally, the supernatant was combined for measurement.

Water-soluble polysaccharide content was measured using the phenol-sulphuric acid colorimetric method (Dubois et al. 1956), using glucose as a standard, with absorbance measured at $490 \mathrm{~nm}$. Concentration of water-soluble polysaccharide was quantitatively determined by the calibration curve. Water-soluble polysaccharide yield per plant was calculated by multiplying the water-soluble polysaccharide content by the leaves biomass per plant.

\section{Statistical analysis}

Data are reported as the mean \pm standard deviation (SD), and all tests were performed using the SPSS ${ }^{\oplus} 16.0$ statistical software package (SPSS, Chicago, IL, USA). A two-way ANOVA model with light quality and light intensity as the main fixed factors plus a light quality $\times$ light intensity interaction term, followed by Tukey's multiplerange test, was performed for biomass accumulation, photosynthesis parameters, and leaf characteristics as well as the water-soluble polysaccharide yields. The data were tested for normality (Shapiro-Wilk normality test) before analysis of variance. All statistical analyses were performed at a $95 \%$ confidence level.

\section{Results}

\section{Variation in growth and biomass} production

Two-way ANOVA showed that both light quality and light intensity treatments, as 
well as the interaction between them significantly affected the biomass production and allocation of C. paliurus (Tab. 1). The total biomass per seedling varied among light intensity treatments with the following order $\mathrm{L}_{3}>\mathrm{L} 2>\mathrm{L} 1$. This trend persisted across the growth of leaves, stem, and $\operatorname{root}($ Tab. 2).

Across three light intensity levels, the highest value of total biomass was achieved at BL, RL and WL treatments (Tab. 2). However, the highest value of leaf biomass was achieved at WL treatment. Compared to $\mathrm{WL}$ treatment, leaf biomass of $\mathrm{RL}, \mathrm{GL}$, $\mathrm{BL}$, and $\mathrm{PL}$ decreased by $40.1 \%, 60.8 \%$, $24.5 \%$, and $54.7 \%$, respectively. Also, the five light quality treatments produced different biomass allocation among the seedlings parts. The highest ratios of leaf to total biomass were observed in treatments $\mathrm{PL}$ (48.7\%) and WL (41.6\%), whereas the greatest ratios of root and stem were achieved in treatment $\mathrm{RL}(76.2 \%), \mathrm{GL}(75.9 \%)$ and $\mathrm{BL}$ (70.9\%), respectively (Tab. 2 ).

\section{Variation in photosynthesis and leaf} characteristics

The seedlings grown under blue light and red light treatments had significantly

Tab. 2 - Tukey's multiple-range test of biomass, water-soluble polysaccharide content and water-soluble polysaccharide yield of Cyclocarya paliurus after a Two-way ANOVA. $L 1, L 2$, and $L 3$ represent three irradiance levels of $500 \pm 30 \mathrm{umol} \mathrm{m}^{-2} \mathrm{~s}^{-1}, 750 \pm 30 \mathrm{umol}$ $\mathrm{m}^{-2} \mathrm{~s}^{-1}$, and $1000 \pm 30 \mathrm{umol} \mathrm{m} \mathrm{m}^{-2} \mathrm{~s}^{-1}$, respectively. (WL): white light; (BL): blue light; $(R L)$ : red light; $(\mathrm{GL})$ : green light; $(\mathrm{PL})$ : purple light.

\begin{tabular}{|c|c|c|c|c|c|c|c|}
\hline \multirow[b]{2}{*}{ Treatment } & \multirow[b]{2}{*}{ Level } & \multicolumn{4}{|c|}{ Biomass (g) } & \multicolumn{2}{|c|}{ Polysaccharide } \\
\hline & & Root & Stem & Leaf & Total & $\begin{array}{l}\text { Content } \\
\left(\mathrm{mg} \mathrm{g}^{-1}\right)\end{array}$ & $\begin{array}{c}\text { Yield } \\
\left(\text { mg plant }^{-1}\right)\end{array}$ \\
\hline \multirow{5}{*}{$\begin{array}{l}\text { Light } \\
\text { quality }\end{array}$} & RL & $2.65^{a}$ & $1.42^{a}$ & $1.27^{c}$ & $5.34^{\mathrm{a}}$ & $34.27^{\mathrm{ab}}$ & $44.52^{c}$ \\
\hline & $\mathrm{GL}$ & $1.73^{b}$ & $0.89^{c}$ & $0.83^{d}$ & $3.45^{\mathrm{b}}$ & $36.75^{\mathrm{a}}$ & $29.29^{d}$ \\
\hline & $\mathrm{BL}$ & $2.67^{a}$ & $1.24^{\mathrm{ab}}$ & $1.60^{\mathrm{b}}$ & $5.51^{a}$ & $34.86^{\mathrm{ab}}$ & $57.55^{a}$ \\
\hline & PL & $0.50^{c}$ & $0.51^{d}$ & $0.96^{d}$ & $1.97^{c}$ & $32.78^{\mathrm{b}}$ & $32.01^{d}$ \\
\hline & WL & $1.78^{\mathrm{b}}$ & $1.20^{\mathrm{b}}$ & $2.12^{a}$ & $5.10^{a}$ & $23.51^{c}$ & $49.49^{b}$ \\
\hline \multirow{3}{*}{$\begin{array}{l}\text { Light } \\
\text { intensity }\end{array}$} & $\mathrm{L} 1$ & $0.76^{c}$ & $0.59^{c}$ & $0.83^{b}$ & $2.18^{c}$ & $27.98^{c}$ & $23.22^{c}$ \\
\hline & L2 & $1.64^{\mathrm{b}}$ & $0.98^{b}$ & $1.58^{a}$ & $4.21^{b}$ & $32.11^{\mathrm{b}}$ & $50.73^{b}$ \\
\hline & L3 & $3.19^{a}$ & $1.58^{\mathrm{a}}$ & $1.66^{\mathrm{a}}$ & $6.43^{a}$ & $37.81^{\mathrm{a}}$ & $62.76^{a}$ \\
\hline
\end{tabular}

higher photosynthetic rate $(\mathrm{Pn})$ and stomatal conductance (gs) values than other light quality treatments (Fig. 2A, Fig. 2B). In the 15 treatments, the highest $P n$ value was detected in treatments $\mathrm{R}_{3}(7.09 \mu \mathrm{mol}$

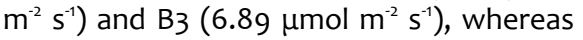
the lowest value was observed in treatment P1 $\left(0.79 \mu \mathrm{mol} \mathrm{m}^{-2} \mathrm{~s}^{-1}\right)$. Two-way ANOVA showed that both light quality and light intensity treatments, as well as the interaction between them significantly affected the $\mathrm{Pn}$ and gs of C. paliurus (Tab. 3). Meanwhile, there was a significant decrease in $\mathrm{Pn}$ and gs under all light qualities over the range of light intensities from $1000 \mu \mathrm{mol}$ $\mathrm{m}^{-2} \mathrm{~s}^{-1}(\mathrm{~L} 3)$ to $500 \mu \mathrm{mol} \mathrm{m}^{-2} \mathrm{~s}^{-1}$ (L1 - Fig. $2 \mathrm{~A}$, Fig. 2B).

Leaf characteristics such as leaf area (LA)
Fig. 2 - Variation in photosynthetic rate $(\mathrm{Pn})(\mathrm{A})$, stomatal conductance (gs) (B), leaf area (LA) (C), and specific leaf mass per area (SLM) (D) of Cyclocarea paliurus under different light quality and intensity treatments (mean \pm SD). . Different lower case letters indicate significant differences between various treatments within a component after Tukey's test ( $\mathrm{p}<$ 0.05). (WL): white light; $(B L)$ : blue light; $(R L)$ : red light; (GL): green light; $(P L)$ : purple light. $L 1, L 2$, and $L 3$ represent three irradiance levels of $500 \pm 30 \mathrm{umol} \mathrm{m}^{-2} \mathrm{~s}$ , $750 \pm 30 \mathrm{umol} \mathrm{m}^{-2} \mathrm{~s}^{-1}$, and $1000 \pm 30 \mathrm{umol} \mathrm{m}^{-2} \mathrm{~s}^{-1}$, respectively.
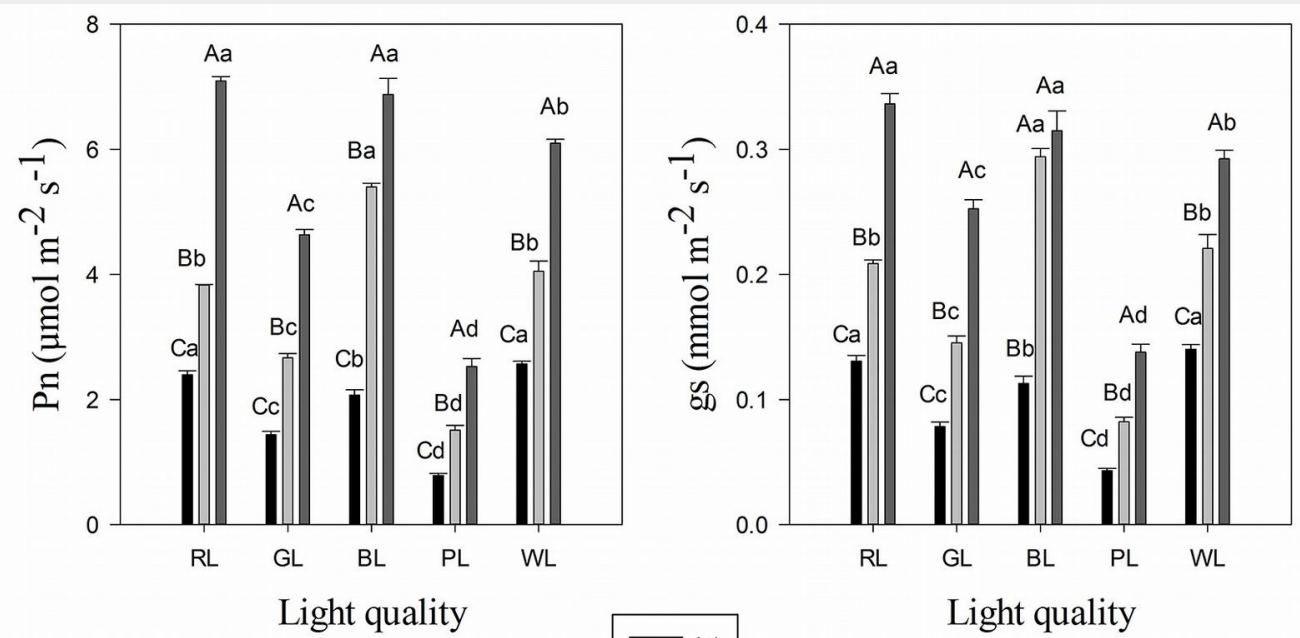

Light quality
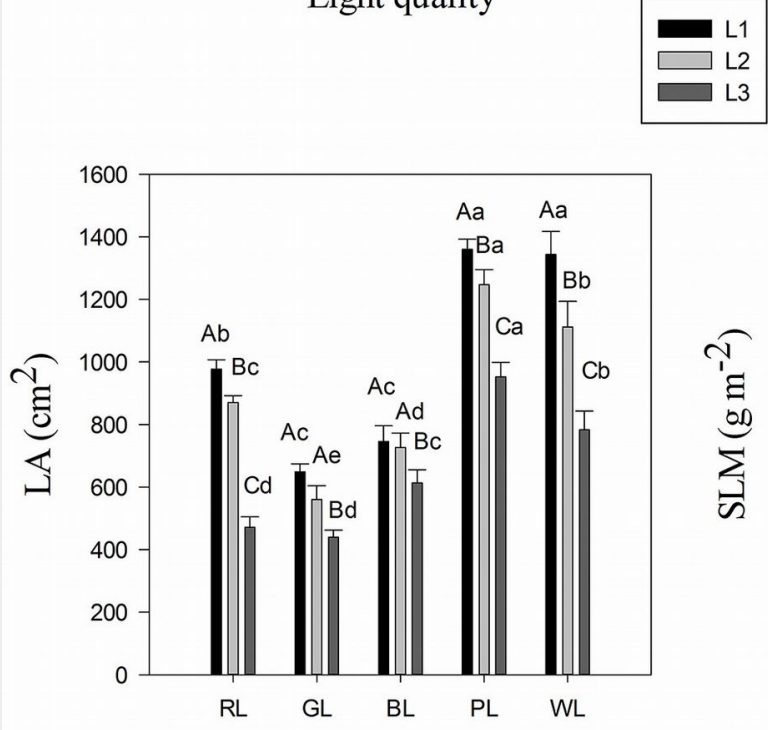

Light quality

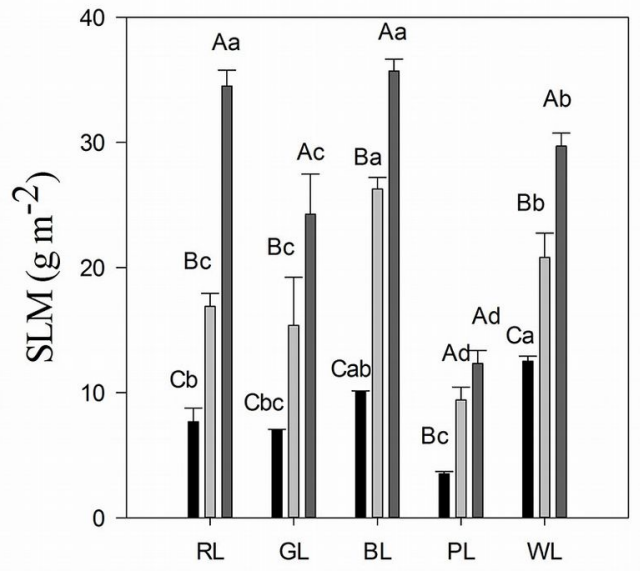

Light quality 
Tab. 3 - Summary of significance levels (Two-way ANOVA) for the effects of light quality, light intensity and their interaction on photosynthetic rate $(\mathrm{Pn})$, stomatal conductance (gs), leaf area (LA), and specific leaf mass per area (SLM) in Cyclocarya paliurus. (df): degrees of freedom; (MS): mean squares.

\begin{tabular}{|c|c|c|c|c|c|}
\hline Source & & 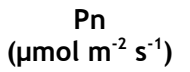 & $\begin{array}{c}\text { gs } \\
\left(\mathrm{mmol} \mathrm{m}^{-2} \mathrm{~s}^{-1}\right)\end{array}$ & $\begin{array}{l}\mathrm{LA} \\
\left(\mathrm{cm}^{2}\right)\end{array}$ & $\begin{array}{c}\mathrm{SLM} \\
\left(\mathrm{g} \mathrm{m}^{-2}\right)\end{array}$ \\
\hline \multirow{3}{*}{$\begin{array}{l}\text { Light quality } \\
\text { (A) }\end{array}$} & df & 4 & 4 & 4 & 4 \\
\hline & MS & 1505.678 & 913.713 & 291.358 & 130.176 \\
\hline & Prob & $<0.001$ & $<0.001$ & $<0.001$ & $<0.001$ \\
\hline \multirow{3}{*}{$\begin{array}{l}\text { Light intensity } \\
\text { (B) }\end{array}$} & df & 2 & 2 & 2 & 2 \\
\hline & MS & 4680.091 & 2838.874 & 234.919 & 546.538 \\
\hline & Prob & $<0.001$ & $<0.001$ & $<0.001$ & $<0.001$ \\
\hline \multirow{3}{*}{$\begin{array}{l}\text { Interaction } \\
(\mathrm{A} \times \mathrm{B})\end{array}$} & df & 8 & 8 & 8 & 8 \\
\hline & MS & 156.876 & 95.179 & 12.882 & 19.190 \\
\hline & Prob & $<0.001$ & $<0.001$ & $<0.001$ & $<0.001$ \\
\hline
\end{tabular}

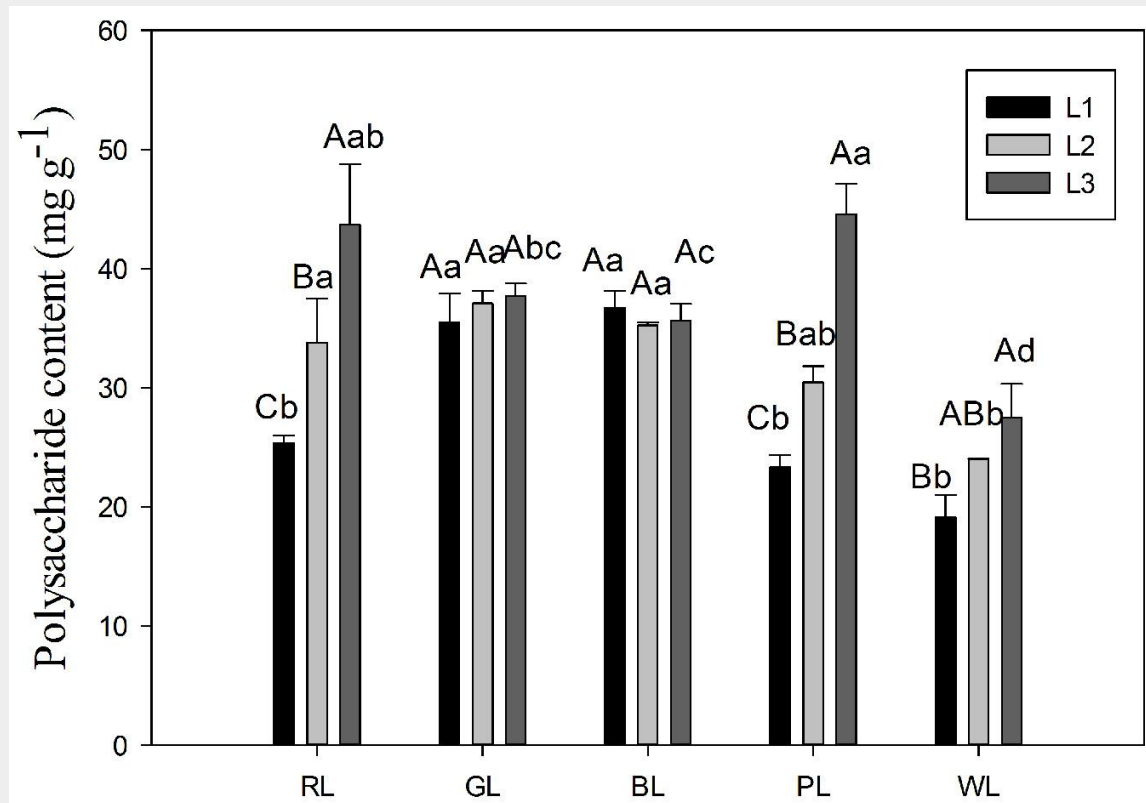

Light quality and specific dry leaf mass per area (SLM) of C. paliurus were found to be significantly different under various light quality and intensity treatments (Fig. 2C, Fig. 2D). Moreover, a significant interaction of light quality and intensity was observed in LA and SLM of C. paliurus (Tab. 3). Light intensity of $500 \mu \mathrm{mol} \mathrm{m} \mathrm{m}^{-1}(\mathrm{~L} 1)$ resulted in the highest LA, and LA was significantly higher in $\mathrm{PL}$ treatment than that in other light quality treatments (Fig. 2C). Variation trend in SLM of C. paliurus was consistent with that of $\mathrm{Pn}$ in leaves. In the 15 treatments, the highest SLM values were detected in treatments $\mathrm{B}_{3}$ (35.69 $\mathrm{g} \mathrm{m}^{-2}$ ) and $\mathrm{R}_{3}$ (34.51 $\mathrm{g}$ $\left.\mathrm{m}^{-2}\right)$, whereas the lowest was observed in treatment $\mathrm{P} 1$ (3.53 $\mathrm{g} \mathrm{m}^{-2}$ - Fig. 2D).
Fig. 3 - Variation in water-soluble polysaccharide content in Cyclocarea paliurus leaves under different light quality and intensity treatments (mean \pm SD). Different lower case letters indicate significant differences between various treatments within a component after Tukey's test $(p<0.05)$. (WL): white light; $(B L)$ : blue light; (RL): red light; $(\mathrm{GL})$ : green light; $(\mathrm{PL})$ : purple light. $L_{1}, \mathrm{~L} 2$, and $\mathrm{L} 3$ represent three irradiance levels of $500 \pm 30 \mu \mathrm{mol} \mathrm{m}^{-2} \mathrm{~s}^{-1}$, $750 \pm 30 \mu \mathrm{mol} \mathrm{m}^{-2} \mathrm{~s}^{-1}$, and $1000 \pm 30 \mu \mathrm{mol}$ $\mathrm{m}^{-2} \mathrm{~s}^{-1}$, respectively.

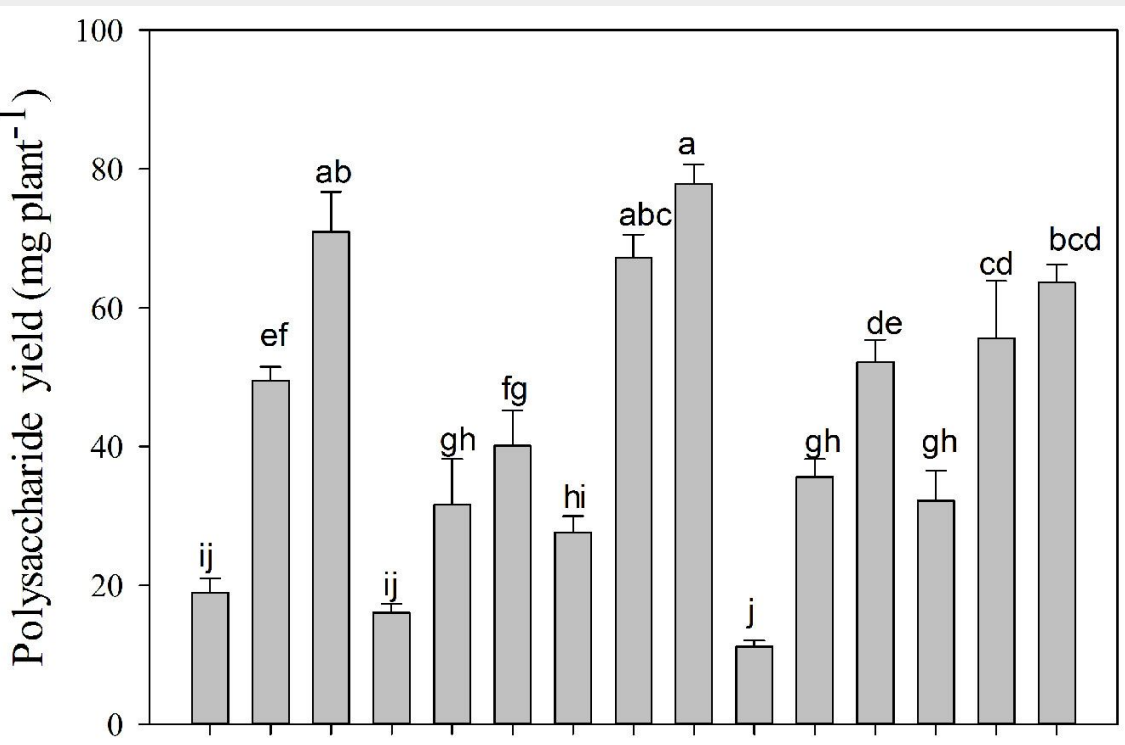

$\begin{array}{llllllllllllll}\text { R1 } & \text { R2 } & \text { R3 } & \text { G1 } & \text { G2 } & \text { G3 } & \text { B1 } & \text { B2 } & \text { B3 } & \text { P1 } & \text { P2 } & \text { P3 } & \text { W1 W2 W3 }\end{array}$
Fig. 4 - Variation in water-soluble polysaccharide yield of Cyclocarya paliurus leaves in different light quality and intensity treatments (mean \pm SD). Different lower case letters indicate significant differences between various treatments within a component ( $p<0.05$ by Tukey's test). (WL): white light; (BL): blue light; (RL): red light; $(G L)$ : green light; $(P L)$ : purple light. Number 1,2 , and 3 represent three irradiance levels of $500 \pm 30 \mu \mathrm{mol} \mathrm{m}^{-2} \mathrm{~s}^{-1}, 750 \pm 30$ $\mu \mathrm{mol} \mathrm{m} \mathrm{s}^{-1}$, and $1000 \pm 30 \mu \mathrm{mol} \mathrm{m} \mathrm{s}^{-1}$, respectively. 
Variation in water-soluble polysaccharide content and yield per plant

The highest water-soluble polysaccharide contents were observed in $\mathrm{P}_{3}(44.58 \mathrm{mg}$ $\mathrm{g}^{-1}$ ) and R3 (43.69 $\mathrm{mg} \mathrm{g}^{-1}$ ) treatments, whereas the lowest contents were found in $\mathrm{P}_{1}\left(23.31 \mathrm{mg} \mathrm{g}^{-1}\right)$ and $\mathrm{W}_{1}\left(19.09 \mathrm{mg} \mathrm{g}^{-1}\right)$ treatments (Fig. 3). Two-way ANOVA showed that both light quality and light intensity treatments, as well as the interaction between them significantly affected water-soluble polysaccharide content of $C$. paliurus leaves (Tab. 1). The water-soluble polysaccharide content in leaves varied among light intensity treatments with the following order $L 3>L 2>L 1$ (Tab. 2).

Based on the leaf biomass and water-soluble polysaccharide content, the integrated effect of light quality and light intensity on the accumulation of water-soluble polysaccharide in leaves per plant was significant ( $p<0.05$ - Fig. 4). The greatest accumulation of water-soluble polysaccharide in the leaves per plant was achieved in

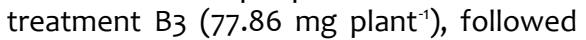
by treatment R3 (70.95 $\mathrm{mg}$ plant $\left.{ }^{-1}\right)$, whereas the lowest was found in treatment P1 (11.18 mg plant $\left.{ }^{-1}\right)$. Compared to treatment B3, water-soluble polysaccharide accumulation in other treatments was decreased by $8.9-85.6 \%$. Moreover, a two-way ANOVA showed that light intensity and light quality treatments as well as their interactions significantly affected water-soluble polysaccharide accumulation of C. paliurus (Tab. 1).

\section{Discussion}

\section{Variation in plant growth and} photosynthesis

It is generally recognized that light intensity and light quality play an important role in plant growth, photosynthetic capacity, as well as various aspects of physiology (Müller et al. 2013, Liu et al. 2015). Typically, optimal light irradiance is central to the productivity of plants, as excessive high or low light intensity often impacts photosynthesis, and then severely limit plant growth (Ma et al. 2015). The present study demonstrated that biomass production of C. paliurus was much lower at light intensity levels of L1 $\left(500 \mu \mathrm{mol} \mathrm{m}^{-2} \mathrm{~s}^{-1}\right)$ and L2 $(750 \mu \mathrm{mol}$ $\left.\mathrm{m}^{-2} \mathrm{~s}^{-1}\right)$ than at $\mathrm{L} 3\left(1000 \mu \mathrm{mol} \mathrm{m} \mathrm{m}^{-2} \mathrm{~s}^{-1}-\right.$ Tab. 2 ), indicating that $C$. paliurus is a heliophyte. The observed growth response of $C$. paliurus to light intensity was similar to that of many tree species, such as Rauvolfia species and Camptotheca acuminata, which were reported to grown better under higher light irradiance (Cai et al. 2009, Ma et al. 2015).

In higher plants, the regulation and perception of the light changes are controlled by a system of photoreceptors, including cryptochromes (blue/UV-A light receptors, 340-520 nm), phytochromes (red/far-red receptors, >520 nm) and phototropins (phot1 and phot2 - Liu et al. 2015). Thus, varying light wavelength produces different growth responses in plants. The per- centage absorption of red or blue light by plant leaves is about 90\% (Terashima et al. 2009), consequently plant development is strongly influenced by red or blue light (McNellis \& Deng 1995). This was supported by data in our study, i.e., there were significantly higher values of total biomass under $B L$ and $R L$ treatments. Similar results were observed in studies of other trees such as C. deserticola (Ouyang et al. 2003) and C. acuminata (Liu et al. 2015).

Photosynthesis, one of the most important chemical processes in higher plants, is directly linked to production of plant biomass, however, photosynthesis of plants is very sensitive to light conditions ( $M a$ et al. 2015). In this study, variation in biomass accumulation in C. paliurus grown under different light quality and intensity treatments were closely linked with photosynthetic rate $(\mathrm{Pn})$. Red light and blue light of $1000 \mu \mathrm{mol} \mathrm{m} \mathrm{m}^{-2} \mathrm{~s}^{-1}$ achieved significantly higher Pn and gs values (Fig. 2), suggesting the photosynthetic rate of $C$. paliurus plants increased under red and blue light, which was consistent with previous reports in other plants such as C. acuminata and cucumber (Liu et al. 2015, Hernández \& Kubota 2016). It has been reported that red light is related with a highly effective light absorption through chlorophyll accumulation for photosynthesis (Evans 1987), while blue light may promote leaf stomatal opening by activating phototropin (Inoue et al. 2010). However, chlorophyll contents and stomatal opening of $C$. paliurus leaves under varying light qualities need to be further studied, as we did not measure them in this study.

The plasticity in leaf morphological and physiological characteristics may be crucial to the success of plant to establish itself in a new environment. Low light intensity may lead to increase in leaf area and seedling height. These changes may maximize the capture of available light to meet the demand for leaf photosynthesis (Steinger et al. 2003). This was supported by the changes of LA in different light quality and intensity treatments, as we observed the highest $L A$ values achieved at light intensity of $500 \mu \mathrm{mol} \mathrm{m} \mathrm{m}^{-2} \mathrm{~s}^{-1}$, especially under white light and purple light (Fig. 2C). Meanwhile, the higher SLM of plant is often considered as an index related to higher leaf photosynthetic capacity and chemical defense (Pearcy \& Sims 1994). Similarly, we suggest that the higher SLM may protect C. paliurus leaves against photoinhibition under blue and red light treatments.

\section{Variation in water-soluble}

\section{polysaccharide accumulation}

The content of phytochemicals is often induced by environmental factors, including light quality and intensity. For example, leaf camptothecin concentrations in C. acuminata display a significantly increase under blue light and 50\% shading treatments (Liu et al. 2015, Hu et al. 2016). Visible light had been reported to induce proantho- cyanidin biosynthesis and affect their composition, whereas UV light specifically induced biosynthesis of flavonols (Koyama et al. 2012). In our previous studies, flavonoids production in C. paliurus plantations had been demonstrated to significantly positively correlate with total solar radiation (Liu et al. 2015). In the present study, water-soluble polysaccharide content in C. paliurus leaves also followed the order L3 $\left(1000 \mu \mathrm{mol} \mathrm{m}^{-2} \mathrm{~s}^{-1}\right)>\mathrm{L} 2(750 \mu \mathrm{mol}$ $\left.\mathrm{m}^{-2} \mathrm{~s}^{-1}\right)>\mathrm{L} 1\left(500 \mu \mathrm{mol} \mathrm{m} \mathrm{m}^{-2} \mathrm{~s}^{-1}-\right.$ Tab. 2$)$. These results support the carbon/nutrient balance theory, i.e., if light becomes limiting, the decline in photosynthesis may limit plant growth and accumulation of carbonbased phytochemicals (Deng et al. 2012).

The effects of light quality on phytochemical accumulation are more complex and often reported with mixed results (Giliberto et al. 2005, Ohashi-Kaneko et al. 2007). In the present study, the highest watersoluble polysaccharide contents were observed at $R L$ and $B L$ treatments across the three light intensity levels, which may due to the higher percentage absorption of red or blue light by leaves of $C$. paliurus and higher photosynthetic rate (Fig. 2A) related with carbohydrate accumulation (Evans 1987). The goal of silvicultral practices is to obtain higher water-soluble polysaccharide yield (equal to water-soluble polysaccharide content multiplied by leaf biomass). In the present study, treatment under RL and $B L$ at $1000 \mu \mathrm{mol} \mathrm{m}^{-2} \mathrm{~s}^{-1}$ were the most effective way to induce the accumulation of water-soluble polysaccharide because it resulted in the highest leaf biomass with the passage of time (Tab. 2, Fig. 4). Overall, in order to achieve the highest water-soluble polysaccharide yield per area in C. paliurus plantations, it is important to manipulate growing conditions such as light intensity and light quality. However, high-yield production of water-soluble polysaccharide in C. paliurus through manipulating light conditions needs to be further confirmed with better designed large-scale field tests.

In conclusion, blue light and red light at $1000 \mu \mathrm{mol} \mathrm{m} \mathrm{m}^{-2} \mathrm{~s}^{-1}$ achieved the highest total biomass, photosynthetic rate and specific leaf dry mass per area in C. paliurus. Meanwhile, treatments under blue light and red light at $1000 \mu \mathrm{mol} \mathrm{m} \mathrm{m}^{-2} \mathrm{~s}^{-1}$ achieved the highest water-soluble polysaccharide yield per plant, due to the higher polysaccharide content and leaf biomass. These results indicate that manipulating light intensity and quality might be an effective means to obtain higher biomass and water-soluble polysaccharide yield in C. paliurus plantations.

\section{Acknowlegements}

We acknowledge financial support from the National Natural Science Foundation of China (No. 31470637), a project funded by the Priority Academic Program Development of Jiangsu Higher Education Institutions (PAPD) and the Doctorate Fellowship Foundation of Nanjing Forestry University. 
WY and $Y L$ equally contributed to this work.

\section{References}

Birari RB, Bhutani KK (2007). Pancreatic lipase inhibitors from natural sources: unexplored potential. Drug Discovery Today 12: 879-889. doi: 10.1016/j.drudis.2007.07.024

Cai ZQ, Wang WH, Yang J, Cai CT (2009). Growth, photosynthesis and root reserpine concentrations of two Rauvolfia species in response to a light gradient. Industrial Crops and Products 30: 220-226. - doi: 10.1016/j.indcrop.2009.03.010 Cope KR, Bugbee B (2013). Spectral effects of three types of white light-emitting diodes on plant growth and development: absolute versus relative amounts of blue light. HortScience 48: 504-509. [online] URL: http://hortsci.ashs publications.org/content/48/4/504.short

Cui G, Zhang W, Zhang A, Mu H, Bai H, Duan J, Wu C (2013). Variation in antioxidant activities of polysaccharides from Fructus jujubae in South Xinjiang area. International Journal of Biological Macromolecules 57: 278-284. - doi: 10.1016/j.ijbiomac.2013.03.013

Deng B, Shang X, Fang S, Li Q, Fu X, Su J (2012). Integrated effects of light intensity and fertilization on growth and flavonoid accumulation in Cyclocarya paliurus. Journal of Agricultural and Food Chemistry 60: 6286-6292. - doi: 10.1021/jf301525s

Deng B, Cao Y, Fang S, Shang X, Yang W, Qian C (2015). Variation and stability of growth and leaf flavonoid content in Cyclocarya paliurus across environments. Industrial Crops and Products 76: 386-393. - doi: 10.1016/j.indcrop. 2015.07.011

Dubois M, Gilles KA, Hamilton JK, Rebers P, Smith F (1956). Colorimetric method for determination of sugars and related substances. Analytical Chemistry 28: 350-356. - doi: 10.1021/ ac60111a017

Evans J (1987). The dependence of quantum yield on wavelength and growth irradiance. Functional Plant Biology 14: 69-79. - doi: 10.1071/ pp9870069

Fan XX, Xu ZG, Liu XY, Tang CM, Wang LW, Han $X L$ (2013). Effects of light intensity on the growth and leaf development of young tomato plants grown under a combination of red and blue light. Scientia Horticulturae 153: 50-55. doi: 10.1016/j.scienta.2013.01.017

Fang S, Wang J, Wei Z, Zhu Z (2006). Methods to break seed dormancy in Cyclocarya paliurus (Batal) Iljinskaja. Scientia Horticulturae 110: 305309. - doi: 10.1016/j.scienta.2006.06.031

Fang S, Chu X, Shang X, Yang W, Fu X, She C (2011). Provenance and temporal variations in selected flavonoids in leaves of Cyclocarya paliurus. Food Chemistry 124: 1382-1386. - doi: 10.1016/j.foodchem.2010.07.095

Fu X, Zhou X, Deng B, Shang X, Fang S (2015). Seasonal and genotypic variation of water-soluble polysaccharide content in leaves of Cyclocarya paliurus. Southern Forests 77: 231-236. doi: 10.2989/20702620.2015.1010698

Giliberto L, Perrotta G, Pallara P, Weller JL, Fraser PD, Bramley PM, Giuliano G (2005). Manipulation of the blue light photoreceptor cryptochrome 2 in tomato affects vegetative development, flowering time, and fruit antioxi- dant content. Plant Physiology 137: 199-208. doi: 10.1104/pp.104.051987

Hernández R, Kubota C (2016). Physiological responses of cucumber seedlings under different blue and red photonflux ratios using LEDs. Environmental and Experimental Botany 121: 66-74. - doi: 10.1016/j.envexpbot.2015

Hu Y, Yu W, Song L, Du XH, Ma X, Liu Y, Ying Y (2016). Effects of light on production of camptothecin and expression of key enzyme genes in seedlings of Camptotheca acuminate Decne. Acta Physiologiae Plantarum 38: 1-9. - doi: 10.1007/s11738-016-2084-z

Huang SQ, Ning ZX (2010). Extraction of polysaccharide from Ganoderma lucidum and its immune enhancement activity. International Journal of Biological Macromolecules 47: 336-341. doi: 10.1016/j.ijbiomac.2010.03.019

Inoue SI, Takemiya A, Shimazaki KI (2010). Phototropin signaling and stomatal opening as a model case. Current Opinion in Plant Biology 13: 587-593. - doi: 10.1016/j.pbi.2010.09.002

Johkan M, Shoji K, Goto F, Hahida S, Yoshihara T (2012). Effect of green light wavelength and intensity on photomorphogenesis and photosynthesis in Lactuca sativa. Environmental and Experimental Botany 75: 128-133. - doi: 10.1016/ j.envexpbot.2011.08.010

Koyama K, Ikeda H, Poudel PR, Goto-Yamamoto $N$ (2012). Light quality affects flavonoid biosynthesis in young berries of Cabernet Sauvignon grape. Phytochemistry 78: 54-64. - doi: 10.1016/ j.phytochem.2012.02.026

Kurihara H, Fukami H, Kusumoto A, Toyoda $\mathrm{Y}$, Shibata H, Matsui Y, Tanaka T (2003). Hypoglycemic action of Cyclocarya paliurus (Batal.) Iljinskaja in normal and diabetic mice. Bioscience, Biotechnology, and Biochemistry 67: 877880. - doi: 10.1271/bbb.67.877

Liu $Y$, Song L, Yu W, Hu Y, Ma X, Wu J, Ying $Y$ (2015). Light quality modifies camptothecin production and gene expression of biosynthesis in Camptotheca acuminata Decne seedlings. Industrial Crops and Products 66: 137-143. - doi: 10.1016/j.indcrop.2014.12.046

Ma X, Song L, Yu W, Hu Y, Liu Y, Wu J, Ying $Y$ (2015). Growth, physiological, and biochemical responses of Camptotheca acuminata seedlings to different light environments. Frontiers in Plant Science 6: 321. [online] URL: http://www. ncbi.nlm.nih.gov/pmc/articles/PMC4424855/

McNellis TW, Deng XW (1995). Light control of seedling morphogenetic pattern. Plant Cell 7: 1749-1761. - doi: 10.1105/tpc.7.11.1749

Müller V, Albert A, Winkler JB, Lankes C, Noga G, Hunsche $M$ (2013). Ecologically relevant UV-B dose combined with high PAR intensity distinctly affect plant growth and accumulation of secondary metabolites in leaves of Centella asiatica L. Urban. Journal of Photochemistry and Photobiology B: Biology 127: 161-169. - doi: 10.1016/j.jphotobiol.2013.08.014

Ohashi-Kaneko K, Takase M, Kon N, Fujiwara K, Kurata K (2007). Effect of light quality on growth and vegetable quality in leaf lettuce, spinach and komatsuna. Environmental Control in Biology 45: 189-198. - doi: 10.2525/ecb.45.189 Ouyang J, Wang X, Zhao B, Wang Y (2003). Light intensity and spectral quality influencing the callus growth of Cistanche deserticola and biosynthesis of phenylethanoid glycosides. Plant
Science 165: 657-661. - doi: 10.1016/S0168-9452 (03)00255-3

Pearcy RW, Sims DA (1994). Photosynthetic acclimation to changing light environments: scaling from the leaf to the whole plant. In: "Exploitation of Environmental Heterogeneity by Plants. Ecophysiological Processes Aboveand Belowground". Academic Press Inc., Boston, MA, USA, pp. 145-174. - doi: 10.1016/B978-012-155070-7.50010-X

Steinger T, Roy BA, Stanton ML (2003). Evolution in stressful environments II: adaptive value and costs of plasticity in response to low light in Sinapis arvensis. Journal of Evolutionary Biology 16: 313-323. - doi: 10.1046/j.1420-9101.2003. 00518.x

Tang H, Hu YY, Yu WW, Song LL, Wu JS (2015). Growth, photosynthetic and physiological responses of Torreya grandis seedlings to varied light environments. Trees 29: 1-12. - doi: 10.1007/ s00468-015-1180-9

Terashima I, Fujita T, Inoue T, Chow WS, Oguchi $R$ (2009). Green light drives leaf photosynthesis more efficiently than red light in strong white light: revisiting the enigmatic question of why leaves are green. Plant and Cell Physiology 50: 684-697. - doi: 10.1093/pcp/pcpo34

Wang DF, Wang CH, Li J, Zhao G (2001). Components and activity of polysaccharides from coarse tea. Journal of Agricultural and Food Chemistry 49: 507-510. - doi: 10.1021/jfooo029m

Xiao J, Huo J, Jiang H, Yang F (2011). Chemical compositions and bioactivities of crude polysaccharides from tea leaves beyond their useful date. International Journal of Biological Macromolecules 49: 1143-1151. - doi: 10.1016/j.ijbiomac. 2011.09.013

Xie MY, Li L, Nie SP, Wang XR, Lee FS (2006). Determination of speciation of elements related to blood sugar in bioactive extracts from Cyclocarya paliurus leaves by FIA-ICP-MS. European Food Research and Technology 223: 202209. - doi: 10.1007/s00217-005-0173-0

Xie JH, Xie MY, Nie SP, Shen MY, Wang YX, Li C (2010). Isolation, chemical composition and antioxidant activities of a water-soluble polysaccharide from Cyclocarya paliurus (Batal.) Iljinskaja. Food Chemistry 119 (4): 1626-1632. doi: 10.1016/j.foodchem.2009.09.055

Xie JH, Liu X, Shen MY, Nie SP, Zhang H, Li C, Xie MY (2013). Purification, physicochemical characterisation and anticancer activity of a polysaccharide from Cyclocarya paliurus leaves. Food Chemistry 136: 1453-1460. - doi: 10.1016/j. foodchem.2012.09.078

Xie J, Wang Z, Shen M, Nie S, Gong B, Li H (2015). Sulfated modification, characterization and antioxidant activities of polysaccharide from Cyclocarya paliurus. Food Hydrocolloids 53: 7-15. - doi: 10.1016/j.foodhyd.2015.02.018

Yan XF, Wang Y, Shang XH, Guo SL, Yu T (2004). Effects of field light intensity and quality on biomass and salidroside content in roots of Rhodiola sachalinensis. Acta Phytoecologica Sinica 24: 674-679. [in Chinese with English abstract] [online] URL: http://en.cnki.com.cn/Art icle_en/CJFDTOTAL-STXB200404002.htm

Yu W, Liu Y, Song L, Jacobs DF, Du X, Ying Y, Wu $J$ (2016). Effect of differential light quality on morphology, photosynthesis, and antioxidant enzyme activity in Camptotheca acuminata 
seedlings. Journal of Plant Growth Regulation: 1-13. - doi: 10.1007/s00344-016-9625-y Zhang J, Huang N, Lu J, Li X, Wang Y, Yang L,
Xiao K (2010). Water-soluble phenolic compounds and their anti-HIV-1 activities from the leaves of Cyclocarya paliurus. Journal of Food and Drug Analysis 18: 398-404. [online] URL: http://search.proquest.com/openview/oda753a ec5f610048fbd346aeoodof6o/1 